\title{
MOLECULAR, GENETIC AND HORMONAL OUTLOOK IN ROOT BRANCHING
}

(review)

\section{E.L. ILINA ${ }^{1}$, A.S. KIRYUSHKIN', V.E. TSYGANOV ${ }^{2}$, K. PAWLOWSKI ${ }^{3}$, K.N. DEMCHENKO1, 2}

\begin{abstract}
${ }^{1}$ V.L. Komarov Botanical Institute RAS, Federal Agency of Scientific Organizations, 2, ul. Professora Popova, St. Petersburg, 197376 Russia, e-mail demchenko@binran.ru (corresponding author);

${ }^{2}$ All-Russian Research Institute for Agricultural Microbiology, Federal Agency of Scientific Organizations, 3, sh. Podbel'skogo, St. Petersburg, 196608 Russia, tsyganov@arriam.spb.ru;

${ }^{3}$ Department of Ecology, Environment and Plant Sciences, Stockholm University, SE-106 91 Stockholm, Sweden ORCID:

Ilina E.L. orcid.org/0000-0003-2799-2014

Tsyganov V.E. orcid.org/0000-0003-3105-8689

Pawlowski K. orcid.org/0000-0003-2693-885X

The authors declare no conflict of interests

Acknowledgements:

Supported financially by Russian Science Foundation (grant № 16-16-00089). Study of the role of auxin in lateral root initiation in Cucurbitaceae was supported by Russian Foundation for Basic Research (grant № 14-04-01413-a) Received November 15, 2016
\end{abstract}

\section{Abstract}

The most important function of any plant root system is the supply of mineral nutrients. The soil is a heterogeneous environment characterized by irregular distribution of nutrients. The branching of the main root which leads to the formation of the root system is regulated by the necessity of compensation for this unpredictable environment. Different types of root systems may reflect different strategies of adaptation of vascular plants to land (L. Kutschera et al., 1997). In recent years, a vast array of experimental data on this subject has been collected. Investigations were carried out on the model plant Arabidopsis thaliana (J.G. Dubrovsky et al., 2001; B. Parizot et al., 2012; J.G. Dubrovsky et al., 2017) as well as on a wide range of crops (cereals, crucifers, gourds, buckwheat etc.). The accumulated data allow the identification of economically important traits of root systems that can be exploited to design breeding strategies to optimize root system function. This review contains an analysis of the current data on cellular, molecular genetic and physiological mechanisms of lateral root initiation and development. The phytohormone auxin performs multiple functions during lateral root initiation (Y. Du et al., 2017). It participates in the earliest stages by determining of competence for the first division by pericycle cells that leads to primordium formation. Furthermore, auxin facilitates the emergence of the primordium from the parental root cortex. Recent studies have shown that the formation of the lateral root begins with the oscillation of auxin concentrations in the basal part of the parental root meristem and the formation of an auxin response maximum in some cells of central cylinder (I. De Smet et al., 2007; K.H. ten Tusscher et al., 2017). The next stage is the specification of founder cells in the pericycle and the subsequent formation of the prebranch site (M.A. Moreno-Risueno et al., 2010). Questions ranging from the mechanisms that determine which pericycle cells can become founder cells for lateral root primordia, the mechanisms of regulation of cell proliferation, the positioning of lateral roots along the axis of the parental root, and hormonal factors and their targets, all leading to the successive development of lateral roots, are discussed in this review. Data on the role of auxin in this process and on the mechanisms of auxin signal transduction in the course of lateral root initiation are provided. The key factors involved in the determination of the competence of pericycle cells to initiate lateral root primordia are the transcription factor GATA23 (B. De Rybel et al., 2010) and the membrane-associated kinase regulator MAKR4 (W. Xuan et al., 2015). Special attention is paid to the role of neighboring cell layers in the control of the initial stages of cell proliferation in the pericycle that result in the formation of a new organ. However, there are a number of families among flowering plants in which the initiation and development of lateral root primordia occurs directly in the parental root meristem (J.G. Dubrovsky, 1986, 1987; K.N. Demchenko et al., 2001; E.L. Ilina et al., 2012). For the first time, data on the key role of auxin in lateral root primordia initiation in these species, in particular in Cucurbitaceae, are presented in this review, and the mechanisms that open the opportunity for early and rapid branching of the main root are discussed. Special attention is paid to evolutionary mechanisms of branching site determination in flowering plants. 
Keywords: auxin, cell proliferation, lateral root initiation, meristem, root branching, root development, transcriptional factors

Numerous studies have shown the relationship between the genetically determined root traits and the productivity of crops [1-3], including that under drought conditions [4]. For selection for improving the properties of root systems, it is necessary to identify those features of the root that allow the plant to use water and nutrients most effectively under different conditions. It is important to identify the genetically determined features of the root, which lead to increased yield and resistance to stress. The success of the selective change in the architecture of the root system in crops depends on the specific feature and nature of its inheritance, as well as on the use of a particular system of farming and soil characteristics [5].

The root system of the plant ensures the absorption of water and nutrients necessary for growth and development, fixing plants in the soil, storage of reserve constituents. In addition, it interacts with the roots of other plants, soil microorganisms and fungi. The root system is a dynamic formation that is affected by environmental factors [6-8]. The ability of the root to adapt in response to a change in the moisture level and the amount of nutrients in the soil makes it possible to study the natural plasticity of the root in order to identify its features, which can increase the yield [9-11]. The study of molecular mechanisms that control the architecture of the root system in crops [5] is also of interest. Strategies of study of the root system development include methods for direct and reverse genetics, the use of Arabidopsis thaliana, Medicago truncatula and Brachypodium distachyon mutants, and identification of loci of quantitative characters that determine the phenotypic variability of the root in populations [12-13].

This review presents current understanding of the molecular genetic mechanisms and key genes involved in the earliest stages of initiation of the primordium of the lateral root. For the first time, we present comparative data on the hormonal mechanisms of initiation of the lateral root in various root zones. Particular attention is paid to the evolutionary mechanisms for determining the location of initiation of the lateral root.

Cell-based mechanism of initiation of the lateral root. The root system consists of the main root and lateral roots of different orders. In most species of flowering plants (monocotyledons and dicotyledons), lateral roots are formed endogenously in the pericycle and extend to the surface much higher than the zone of extension of the maternal root $[14,15]$. In the apical meristem of the root, the initial cells proliferate, separating the sister cells that are constantly moving away from the root tip (the age structure of the cells along the root axis), pass from the apical meristem to the stretch zone, reaching a finite size, and acquire functional characteristics of their type in the differentiation zone [16-18]. The study of $l \mathrm{hw}$, wol and ivad mutants in Arabidopsis showed that the heterogeneity of the pericycle and the organization of conducting tissues are regulated by the same cascade of genes and are determined in the meristem at the early stages of development [19]. The first cellular events in the initiation of the lateral root, which include the migration of the nucleus of two neighboring cells of the pericycle and subsequent unequal division of these cells, in Arabidopsis are detected at a distance of several millimeters from the root tip [20, 21]. Despite this, the group of pericycle cells opposite to the xylem pole, which will take part in the initiation, is also determined in the basal part of the apical meristem of the root [22-24].

The role of auxin in the regulation of the initial stages of initiation of the lateral root. Auxin plays a leading role in regulation of the development of the lateral root [25-28]. The family of proteins-repressors of 
Aux/IAA auxin signaling suppresses the work of the ARF (Auxin Response Factor) transcriptional factors group. At physiologically low auxin concentrations, Aux/IAA proteins form dimers with ARF transcriptional factors, preventing their binding to DNA and transcription of auxin-sensitive genes. Auxin regulates morphogenetic processes through rapid ubiquitin-mediated degradation of Aux/IAA proteins. At physiologically high concentrations, it binds to the receptor F-box protein TIR1 (Transport Inhibitor Response 1), which is included in the oligomeric complex SCFTIR1 with ubiquitin-ligase activity [30], which leads to proteolytic degradation of Aux/IAA in the $26 \mathrm{~S}$ proteasome and release of the transcriptional factors ARF [31]. In Arabidopsis, Aux/IAA and ARF proteins are encoded by extensive gene families. Growth processes are regulated through a specific interaction between conjugate synthesized ARF and Aux/IAA proteins.

The most important question in the study of the morphogenesis of the root system is which genetic factor or group determines the program for the development of the founder cells of the lateral root and regulates the spatial distribution of primordia along its longitudinal axis. I. De Smet et al. [23] showed that the cellular response to auxin oscillates in the basal part of the root meristem at intervals of 15 hours, which reflect peaks in the activity of the auxinsensitive DR5 promoter. It is believed that this particular oscillation serves as a mechanism that determines the marking of the initial primordium cells of the lateral root [33].

Genetic targets for auxins. The transcriptional factor GATA23 is one of the targets of the mediated ARF action of auxin in the founder cells of the lateral root in Arabidopsis [34-36]. GATA23 relates to the B-class of GATA proteins and is characterized by the degenerated domain of LLM (leucineleucine-methionine). The GATA23 gene is specific for Brassicaceae; its orthologs have not yet been identified in other families [37, 38]. GATA23, identified in connection with initiation of the lateral root in the meta-analysis of transcriptomic databases in Arabidopsis, is the earliest indicator of lateral root development [36, 39]. GATA23 is expressed in all pericycle cells at the end of the stretch zone, and in pericyclic founder cells expression occurs before their first asymmetric division initiating the lateral root. In RNAi plants with suppression of GATA23 expression, the number of primordia of lateral roots decreases (both left from the maternal root and stopped in development at earlier stages). Increased expression of GATA23 leads to an increase in the frequency of ectopic primordia formation and previous increase in the number of founder cells of the lateral root.

As a result of the study of consecutive time points of expression of the auxin-sensitive structures $p D R 5:: G U S$ and $p G A T A 23:: G U S$ in the roots of Arabidopsis, a relationship between the expression of GATA23 and the cellular response to exogenous auxin processing was established [36]. In the basal part of the meristem, the oscillating peaks of $p D R 5:: G U S$ activity in the protoxylem cells and the related local expression of $p G A T A 23:: G U S$ in the cells of the pericycle of the xylem pole begin 10 hours after the peak of the cellular response to auxin, which is approximately equal to the duration of the mitotic cycle. Therefore, the expression of $p G A T A 23:: G U S$ depends on the TIR1-mediated pathway of the auxin signal transmission in the basal part of the meristem.

A study of the expression of GATA23 in aux/iaa Arabidopsis mutants showed that both the relative expression and the promoter activity of the GATA23 gene were reduced only in the mutant with overexpression of the iaa28-1 gene. In iaa 28-1 mutants, the number of primordia of lateral roots decreased; hence, the expression of the $I A A 28$ gene is related to the mechanism for forming the competence of pericycle cells to the formation of lateral roots. The ectopic expression of 
GATA23 in the pericycle cells of the xylem pole in iaa28-1 leads to a phenocopy of the wild type [34]. That is, the GATA23 protein as a component of the TIR1IAA28 signaling system works after IAA28. A number of ARF factors (ARF5, ARF6, ARF7, ARF8 and ARF19), interacting with the IAA28 protein and synthesized in the basal part of the meristem, have also been detected. The expression of GATA23 was completely absent in the double mutants arf7arf19, which indicates the involvement of ARF7 and ARF19 in activation of GATA23 and initiation of the lateral root. Thus, the first molecular component of the specification of the pericycle cell was identified, which establishes the competence of the pericycle cells in the basal part of the meristem to participation in the initiation of the lateral root. The expression of the GATA23 gene is considered to be the earliest event associated with the initiation of the primordium of the lateral root. GATA23 controls the initial stage of the specification of the founder cells of the root, although its expression is not localized only in them. A mechanism by which the oscillation of maxima of auxin concentration and expression of GATA23 are precisely established and correlated in the meristem of the stretch zone is of interest [15]. It is necessary to identify the positional signals, due to which the specification of the pericycle cells occurs and the competence to the formation of lateral root is formed.

It was also shown that indole acetic acid (IAA) formed in the root cap of indole-3-butyric acid (IBA) modulates the amplitude of the oscillation of IAA concentration in the root meristem [40, 41]. This oscillation, in turn, determines whether a competence zone will be created for the formation of the lateral root (the so-called prebranch site) [42]. Studies of the Arabidopsis transcriptome have made it possible to identify a new, regulated IBA root marking component MEMBRANE-ASSOCIATED KINASE REGULATOR4 (MAKR4) [41]. It transforms competent cells into the initial cells of the future primordium of the lateral root. In the authors' opinion, the space-time root marking is determined by the transformation of IBA into IAA in a cap and the subsequent launch of MAKR4 expression [41]. In addition, AtMYB93 from the subfamily R2R3 MYB (MYELOBLASTOSIS), the expression of which is induced by exogenous auxin in the basal meristem, can be potentially involved in the formation of oscillations of the endogenous auxin and specification of the initial cells of the primordium [43]. These studies allowed suggesting the concept of prebranch sites, the appearance of which is regulated by cyclic apoptosis of the root cap cells [44].

Control of the resumption of the cell cycle. Asymmetric divisions of the pericycle cells, which in the future will give rise to the primordium of the lateral root, are controlled by the activity of the cell cycle [45-50]. In $A r-$ abidopsis and other flowering plants, in which primordia are formed above the stretch zone, in order to implement the program of the lateral root initiation, it is necessary for pericycle cells to leave the cell cycle in the G1 phase [46, 51-52] at the end of the meristem. However, before asymmetric division, they must be ready to resume proliferation $[51,53]$. It is assumed that the $A B E R R A N T L A T$ ERAL ROOT FORMATION 4 (ALF4) gene, encoding a poorly studied protein with nuclear localization [47], is important in order to determine the ability of pericycle cells to continue proliferation. In alf4 mutants, the initiation of the lateral root was disrupted [27, 45, 47]. The functional role of ALF4 is still poorly understood. In alf4 mutants, the formation of calluses is also disrupted [54]. ALF4 is probably needed to ensure the competence of pericycle cells to resume proliferation when forming a lateral root above the stretch zone. The presence of the product of this gene allows the cells to be in a state of temporary rest before the first division, which initiates primordium of the lateral root.

The transition of a portion of the pericycle cells at the xylem pole above 
the stretch zone from the stage $G_{1}$ to the stage $S$ (resumption of proliferation) and their subsequent division are stimulated by auxin. These cells resume the mitotic cycle after reaching the initiation zone of the lateral roots [51, 55]. Most likely, switch genes activating the mitotic cycle are not able to start the process of forming the lateral root without additional stimulation with auxin [48].

SKP2A (S-Phase Kinase-Associated Protein 2A) is an Arabidopsis F-box protein that regulates the proteolysis of transcription factors affecting the mitotic cycle. Auxin activates ubiquitin-dependent degradation of SKP2A protein by directly binding to it. SKP2A stimulates the degradation of E2FC/DPB and induces the proliferation of root meristem cells. Also, auxin enhances the interaction between SKP2A and DPB. That is, SKP2A is an auxin-binding protein that coordinates the transmission of the auxin signal with cell proliferation [56].

The transcriptional factor E2F stimulates the transition to asymmetric cell divisions during the initiation of the lateral root [49, 57]. The expression of $E 2 F a$ is regulated by the dimer of the transcriptional factors LBD18/LBD33, which in turn is associated with the transmission of the auxin signal [57]. LBD18/LBD33 serves as a link for the formation of the lateral root by activating the transcription of $E 2 F a$. The initiation of transcription of $E 2 F a$ by LBD factors is a common mechanism of auxin-dependent activation of the mitotic cycle [57].

The formation of the competence to initiate the lateral root (prebranch sites) in the pericycle cells in the basal part of the meristem occurs, in the opinion of some authors, due to the formation of a local maximum of auxin in the adjacent protoxylem cells [23]. This blocks the transition to the $\mathrm{S}$ phase in the cells of the pericycle. Such cells leave the meristem at the end of the $G_{1}$ phase and at the end of the stretch zone, and are able to resume cyclic motion, resulting in two synchronous divisions initiating the lateral root [51]. Subsequently, the ability of the pericycle to resume proliferation is determined with the participation of D-type cyclin $C Y C D 4 ; 1$ [58]. A decrease in the expression of $C Y C D 4 ; 1$ in the pericycle under the influence of the local maximum of auxin in the basal part of the meristem leads to a stop in the proliferation of some pericycle cells in $\mathrm{G}_{1}$ (before DNA synthesis) [59]. In the formation of primordia of the lateral root above the stretch zone, the resumption of the pericycle cells motion in the $\mathrm{S}$ phase is accompanied by the formation of a new local maximum of auxin due to its transport from the endoderm [60]. This allows continuing the proliferation of cells and forming an axis of primordium. Thus, the synchronous priming of two adjacent pericycle cells determines the point of initiation of the lateral root. In our opinion, it is the simultaneous resumption of proliferation through the transition from $G_{1}$ to $S$ in these cells and the cells of two adjacent rows of the pericycle determines the exact location of initiation of the formation of the lateral root.

Role of the cell environment in the initiation of the lateral root. In the recent time, the regulatory role of the cell environment of the pericycle in the initiation zone of the lateral root has been widely discussed in the literature [60-64]. The function of mechanical interactions between the pericycle and endoderm cells in the process of initiation and development of the lateral root was studied [64]. It was shown that even before the first division leading to its initiation, the growth and increase in the volume (protrusion) of two adjacent pericyclic cells and the simultaneous decrease in the adjacent endoderm cells occur. Further, the expression of the GATA23 gene is activated and the first unequal anticlinal division occurs. Auxin signal from pericycle cells should be perceived in endoderm cells. In order to study this relationship, the Arabidopsis CASP1pro::shy2-2 line was created, which has a specific suppression of the response to auxin in endoderm cells [64]. SHORT HYPOCOTYL 2 
( $S H Y 2$ ), the gene of repressor of the auxin response, was controlled by the promoter of the CASP1 gene, the protein of which is associated with Casparian strips. In plants expressing the CASP1pro::shy2-2, the development of the lateral roots was blocked until the first asymmetric division. Processing such plants with exogenous auxin (naphthylacetic acid) induced the development of a small number of lateral roots, but primordia did not reach the root surface and were flat, which indicates the need of the response to the auxin in the endoderm cells in order to release the lateral root. Indeed, endodermal cells in CASP1pro::shy2-2 plants remained bulky, although they normally decrease and allow the lateral root to grow.

With the disruption of the endoderm by the laser, proliferation in the pericycle resumed; however, the division plan changed from anticlinal to periclinal, and the development program of the lateral root primordium did not start [63]. The resumption of proliferation in the cells of the pericycle occurred regardless of their position on the longitudinal axis of the root. The disruption of xylem, bark and rhizodermis cells did not affect the resumption of divisions in the pericycle. In the authors' opinion, all the pericycle cells in Arabidopsis are potentially capable of resuming proliferation, but adjacent endoderm cells block this transition [63]. Indirectly, this is confirmed by the ability of the roots of $A r$ abidopsis, as well as other representatives of Brassicaceae, to form multiple lateral roots after treatment with auxins in high concentrations (up to $90 \mu \mathrm{M}$ ) [65, 66].

In Arabidopsis yucca mutants with increased auxin biosynthesis [67, 68], endoderm disruption did not lead to a change in the plan of pericycle cells division from anticlinal to periclinal [63]. In mutants for the transmission of the auxin signal tir1/afb2/afb3 (transport inhibitor1/auxin signaling f-box2/afb3) and slr/iaa14 (solitary root/indole-3-acetic acid14) with multiple root development disruptions in the destruction of the endoderm, the pericycle cells changed the division plan into periclinal, as well as in wild-type roots. However, when processing the roots of the tirl/afb2/afb3 mutant with exogenous auxin, the number of reorientations of divisions decreased. The treatment of wild-type roots with a destroyed endoderm with naphthylphthalamic acid (auxin transport blocker) did not affect the change in the plan of pericycle cells division. When the endoderm was destroyed, they became periclinal, as in control plants. Perhaps the change in the plan of the pericycle cells division depends on the preservation of the pathway for the transmission of the auxin signal, but not on the auxin transport [63].

A local increase in the auxin content in the group of pericycle cells not only forms their competence for the lateral root initiation, but also starts response to auxin in adjacent endoderm cells [60]. In the latter, a short-term expression of the auxin gene of the PIN3 transporter occurs, and the synthesized protein is localized on the membrane of the endodermal cell in contact with the pericycle cell. This ensures the outflow of auxin from the endoderm cells to the pericycle cells. The level of expression of PIN3 in the endoderm begins to decrease 15 hours after the first initiating division, and after 2 hours the protein completely disappears. In the mutant pin3, an increase in the number of pericycle cells with a maximum of auxin and a decrease in the number of the first asymmetric divisions were observed. The PIN3 gene mutation disrupts the transition of the founder cells to the division, initiating primordium. Therefore, due to PIN3-mediated outflow of auxin from the endoderm, the amount of this hormone in the pericycle cells increases again, which stimulates their transition to the first asymmetric division.

Mechanism for determining the size and shape of the primordium of the lateral root. The number of cells participating in the divisions that specify the diameter of the primordium is limited by the receptorlike ACR4 kinase [69]. The volume of primordium is obtained due to the peri- 
clinal divisions, increasing the number of layers. At this stage, the formation of a correct dome-shaped primordium is regulated by several mechanisms, including through a directed auxin flow [63]. The MYB36 gene is expressed in the pericycle at the base of the primordium, which begins at the stage $\mathrm{V}$ of development [70]. It was shown that $M Y B 36$ directly participates in the control of the borders of the primordium, since the myb36-5 mutant has increased number of cells along the width of the primordium. MYB36 is required for the transition from flat to domed shaped primordium. At the same time, cell divisions stop at the periphery and the final width of the primordium is determined. The expression of MYB36 at the level of mRNA and protein occurs in some pericycle cells without transmitting signals to the surrounding endodermal cells, as shown for the SHY2-mediated response to auxin [60, 64].The expression of the PER9 and PER64 peroxidase genes belonging to secondary targets of MYB36 is greatly reduced in the myb36-5 mutant. Probably, as a result of the above, it has a higher content of hydrogen peroxide, since the treatment with potassium iodide (peroxide absorber) resumed the development of primordium in mutant roots. Thus, the final size and shape of primordium depend on the sum of the signals that stimulate or inhibit the proliferation in its cells. These signals include active forms of oxygen, the amount of which is indirectly regulated by the MYB36 gene.

The data presented show that the main genetic processes of determining the competence of pericycle cells and initiation of primordium of the lateral root in Arabidopsis have been sufficiently studied. However, there is a group of plants in which initiation and development of primordium of the lateral roots occur directly in the apical meristem of the main root. This type of the lateral roots formation is characteristic for species from the Cucurbitaceae [71-75], Polygonaceae [76], and Convolvulaceae families, and some aquatic plants from the Pontederiaceae [75, 78] and Araceae [79] families. In addition, due to the formation of groups of primordium of the lateral roots in embryogenesis, these species undergo an early branching of the main root during germination [72, 80]. Rapid development of a powerful root system makes it possible to successfully compete with representatives of other species for soil resources and to gain significant biomass. The regulation of root formation in these plants has not been studied.

The results obtained by us in studying the cellular and hormonal mechanisms of the initiation of the lateral root of courgette (Cucurbita pepo) clearly indicate that the initial stages of the determination of the pericycle and endoderm cells, as well as their transition to the first anticlinal division in the species of the Cucurbitaceae family, are identical to the processes in Arabidopsis and other plants initiating the lateral root above the stretch zone [81]. Thus, the first stage of determination is the appearance of a local maximum of the cellular response to auxin in pairs of sister cells of three internal rows of the pericycle, two rows of the outer pericycle, and a row of endoderm. For Arabidopsis, simultaneous activation of cell pairs of three rows of the pericycle on the xylem pole was shown [55]. In courgette, the first anticlinal division is preceded by the formation of a local maximum of the cellular response to auxin in two adjacent cells in the row. In Arabidopsis and cereals, in addition, there is a directed movement of the nucleus of these cells towards each other [36, 73].

Consequently, the first divisions initiating the lateral root, regardless of the place of its initiation, are the anticlinal divisions of a pair of sister cells. Some difference between the representatives of Cucurbitaceae is the absence of unequal anticlinal divisions and migration of nucleus, since all the initiation processes take place in the root meristem and the cells do not stretch. According to 
our data, in the courgette when initiating the lateral root in the meristem, there is no resumption of the mitotic cycle from the $G_{1}$ phase, as in the formation of the lateral root above the stretch zone $[51,53]$. As a result of one of the anticlinal divisions in the pericycle row (as for the endoderm), two sister cells of origin are formed. Their further advancement along the mitotic cycle $G_{1}-S-G_{2}$ will be accompanied by the occurrence of a local maximum of auxin and will be finished with the first anticlinal division. It will be the first division in the initiation of the primordia of the lateral root.

Thus, we assume that the physiological and molecular genetic mechanisms of initiation of the lateral root in different groups of plants have a single origin. Ancestral forms of all flowering plants had endogenously formed rudiments of lateral roots, and the site of initiation of the lateral root was located in the immediate vicinity of the initial cells of the apical meristem. In the course of evolution, the site of initiation of the lateral root gradually shifted from the apex cells to the basal part from the meristem of the parent root beyond the stretch zone. However, in some families of flowering plants, the archaic type of initiation of the lateral root preserved, i.e. directly in the apical part of the meristem of the parent root. When the site of initiation changed, there was also a decrease in the role of tissues surrounding the pericycle in the formation of temporary primordium structures.

So, in the studies of cellular, molecular genetic and physiological mechanisms of initiation and formation of lateral roots, extensive factual material has been accumulated, but many processes accompanying the formation of a new organ on the maternal root still need to be studied. We still do not know how the cells of origin of the lateral root receive a signal and what leads to the determination of competence of the cell to further formation of the lateral root in this place. Studies of regulatory gene networks have only begun. The prompt resolution of these issues will allow us to proceed to the selection based on the characteristics that determine the ability of root systems to better adapt to changing environmental conditions, and, ultimately, to increase yields.

\section{REFEREN C ES}

1. Ke 11 D.B. Breeding crop plants with deep roots: their role in sustainable carbon, nutrient and water sequestration. Ann. Bot., 2011, 108(3): 407-418 (doi: 10.1093/aob/mcr175).

2. Hufnagel B., de Sousa S.M., Assis L., Guimaraes C.T., Leiser W., Azevedo G.C., Negri B., Larson B.G., Shaff J.E., Pastina M.M., Barros B.A., Weltzien E., Rattunde H.F.W., Viana J.H., C 1 a rk R.T., Falcão A., Gazaffi R., Garcia A.A.F., $\mathrm{Sch}$ affert R.E., Ko chian L.V., M a galhaes J.V. Duplicate and conquer: Multiple homologs of PHOSPHORUS-STARVATION TOLERANCE1 enhance phosphorus acquisition and sorghum performance on low-phosphorus soils. Plant Physiol., 2014, 166(2): 659-677 (doi: 10.1104/pp.114.243949).

3. Narayanan S., Mohan A., Gill K.S., Prasad P.V.V. Variability of root traits in spring wheat germplasm. PLoS ONE, 2014, 9(6): e100317 (doi: 10.1371/journal.pone.0100317).

4. Uga Y., Sugimoto K., Ogawa S., Rane J., Is hitani M., Hara N., Kitomi Y., Inukai Y., Ono K., Kanno N., I noue H., Takehisa H., Motoyama R., Naga mura Y., Wu J., Matsumoto T., Takai T., Okuno K., Yano M. Control of root system architecture by DEEPER ROOTING 1 increases rice yield under drought conditions. Nat. Genet., 2013, 45(9): 1097-1102 (doi: 10.1038/ng.2725).

5. Me ister R., Rajani M.S., Ruzicka D., Schachtman D.P. Challenges of modifying root traits in crops for agriculture. Trends Plant Sci., 2014, 19(12): 779-788 (doi: 10.1016/j.tplants.2014.08.005).

6. Bao Y., Aggarwal P., Robbins N.E., Sturrock C.J., Thompson M.C., Tan H.Q., Tham C., Duan L., Rodriguez P.L., Vernoux T., Mooney S.J., Bennett M.J., Dinneny J.R. Plant roots use a patterning mechanism to position lateral root branches toward available water. PNAS, 2014, 111(25): 9319-9324 (doi: 10.1073/pnas. 1400966111).

7. Tikhonovich I.A., Provorov N.A. Microbiology is the basis of sustainable agriculture: an opinion. Ann. Appl. Biol., 2011, 159(2): 155-168 (doi: 10.1111/j.1744-7348.2011.00489.x). 
8. Paw lowski K., De m c he nko K.N. The diversity of actinorhizal symbiosis. Protoplasma, 2012, 249(4): 967-979 (doi: 10.1007/s00709-012-0388-4).

9. Kano M., Inukai Y., Kitano H., Yamauchi A. Root plasticity as the key root trait for adaptation to various intensities of drought stress in rice. Plant Soil, 2011, 342(1-2): 117-128 (doi: 10.1007/s11104-010-0675-9).

10. Grossman J.D., Rice K.J. Evolution of root plasticity responses to variation in soil nutrient distribution and concentration. Evolutionary Applications, 2012, 5(8): 850-857 (doi: 10.1111/j.1752-4571.2012.00263.x).

11. Ly n c h J. Root architecture and plant productivity. Plant Physiol., 1995, 109(1): 7-13 (doi: 10.1104/pp.109.1.7).

12. Z hu J., Ka e p p le r S., Ly n c h J. Mapping of QTL controlling root hair length in maize (Zea mays L.) under phosphorus deficiency. Plant Soil, 2005, 270(1): 299-310 (doi: 10.1007/s11104-004-1697-y).

13. Kamoshita A., Zhang J., Siopongco J., Sarkarung S., Nguyen H.T., Wade L.J. Effects of phenotyping environment on identification of quantitative trait loci for rice root morphology under anaerobic conditions. Crop Sci., 2002, 42(1): 255-265 (doi: 10.2135/cropsci2002.2550).

14. M a la my J.E., B e $\mathrm{nfey}$ P.N. Organization and cell differentiation in lateral roots of Arabidopsis thaliana. Development, 1997, 124(1): 33-44.

15. Yad a v S.R., B is hop p A., He la ri utt a Y. Plant development: early events in lateral root initiation. Current Biology, 2010, 20(19): R843-R845 (doi: 10.1016/j.cub.2010.09.010).

16. Dolan L., Janmaat K., Wille ms en V., Linstead P., Poethig S., Roberts K., $\mathrm{S}$ c he res B. Cellular organisation of the Arabidopsis thaliana root. Development, 1993, 119(1): 71-84.

17. I v a n o v V.B. Kletochnye osnovy rosta rastenii [Cellular aspects of plant growth]. Moscow, 1974 (in Russ.).

18. D e m c he n k o N.P. Tsitologiya, 1984, 26(4): 382-391 (in Russ.).

19. Parizot B., Laplaze L., Ricaud L., Boucheron-Dubuisson E., Bayle V., Bonke M., De Smet I., Poethig S.R., Helariutta Y., Haseloff J., Chriqui D., B e e ckman T., Nuss a m e L. Diarch symmetry of the vascular bundle in Arabidopsis root encompasses the pericycle and is reflected in distich lateral root initiation. Plant Physiol., 2008, 146(1): 140-148 (doi: 10.1104/pp.107.107870).

20. Peret B., Larrieu A., B e n net t M.J. Lateral root emergence: a difficult birth. J. Exp. Bot., 2009, 60(13): 3637-3643 (doi: 10.1093/jxb/erp232).

21. Casimiro I., M a rchant A., Bhalerao R.P., Beeckman T., Dhooge S., Swarup R., Graham N., Inze D., Sandberg G., Casero P.J., Bennett M. Auxin transport promotes Arabidopsis lateral root initiation. Plant Cell, 2001, 13(4): 843-852 (doi: 10.1105/tpc.13.4.843).

22. B e e mster G.T.S., Fiorani F., Inze D. Cell cycle: the key to plant growth control? Trends Plant Sci., 2003, 8(4): 154-158 (doi: 10.1016/S1360-1385(03)00046-3).

23. De Smet I., Tetsumura T., De Rybel B., Frey N.F.d., Laplaze L., Casimiro I., Swarup R., Naudts M., Vanneste S., Audenaert D., Inze D., B ennett M.J., $\mathrm{B}$ e e c k m a n T. Auxin-dependent regulation of lateral root positioning in the basal meristem of Arabidopsis. Development, 2007, 134(4): 681-690 (doi: 10.1242/dev.02753).

24. te n Tuss che r K.H., Lask owski M. Periodic lateral root priming, what makes it tick. The Plant Cell, 2017 (doi: 10.1105/tpc.16.00638).

25. Overvoorde P., Fukaki H., B e e ck man T. Auxin control of root development. Cold Spring Harbor Perspectives in Biology, 2010, 2(6): 2:a001537 (doi: 10.1101/cshperspect.a001537).

26. Pariz ot B., B e e k man T. Genomics of root development. In: Root genomics and soil interactions. M. Crespi (ed.). Blackwell Publishing Ltd., Oxford, UK, 2012: 3-28 (doi: 10.1002/9781118447093.ch1).

27. Dubrovsky J.G., Sauer M., Napsucialy-Mendivil S., Ivanchenko M.G., Friml J., Shishkova S., Celenza J., Benkova E. Auxin acts as a local morphogenetic trigger to specify lateral root founder cells. PNAS, 2008, 105(25): 8790-8794 (doi: 10.1073/pnas.0712307105).

28. D u Y., Scheres B. Lateral root formation and the multiple roles of auxin. Journal of Experimental Botany, 2017 (doi: 10.1093/jxb/erx223).

29. Tiwari S.B., Wang X.-J., Hage n G., Guilfoy le T.J. AUX/IAA proteins are active repressors, and their stability and activity are modulated by auxin. The Plant Cell, 2001, 13(12): 2809-2822 (doi: 10.1105/tpc.010289).

30. Dharmasiri N., Dharmasiri S., Estelle M. The F-box protein TIR1 is an auxin receptor. Nature, 2005, 435(7041): 441-445 (doi: 10.1038/nature03543).

31. Mockaitis K., Estelle M. Auxin receptors and plant development: A new signaling paradigm. Ann. Rev. Cell Dev. Biol., 2008, 24(1): 55-80 (doi: 10.1146/annurev.cellbio.23.090506.123214).

32. Hamann T., Benkova E., Baurle I., Ki entz M., Jurgens G. The Arabidopsis BODENLOS gene encodes an auxin response protein inhibiting MONOPTEROS-mediated embryo patterning. Genes and Development, 2002, 16: 1610-1615 (doi: 10.1101/gad.229402). 
33. Moreno-Risueno M.A., Van Norman J.M., Moreno A., Zhang J., Ahnert S.E., $\mathrm{B}$ e $\mathrm{nfey}$ P.N. Oscillating gene expression determines competence for periodic Arabidopsis root branching. Science, 2010, 329(5997): 1306-1311 (doi: 10.1126/science.1191937).

34. Rogg L.E., Las s we 11 J., B a rte 1 B. A gain-of-function mutation in IAA28 suppresses lateral root development. Plant Cell, 2001, 13(3): 465-480 (doi: 10.1105/tpc.13.3.465).

35. Brady S.M., Orlando D.A., Lee J.-Y., Wang J.Y., Koch J., Dinneny J.R., Mace D., Ohler U., Benfey P.N. A high-resolution root spatiotemporal map reveals dominant expression patterns. Science, 2007, 318(5851): 801-806 (doi: 10.1126/science.1146265).

36. De Rybel B., Vassileva V., Parizot B., Demeulenaere M., Grunewald W., Audenaert D., Van Campenhout J., Overvoorde P., Jansen L., Vanneste S., Möller B., Wilson M., Holman T., Van Isterdael G., Brunoud G., Vuylsteke M., Vernoux T., De Veylder L., Inzé D., Weijers D., Bennett M.J., Beeckman T. A novel Aux/IAA28 signaling cascade activates GATA23-dependent specification of lateral root founder cell identity. Curr. Biol., 2010, 20(19): 1697-1706 (doi: 10.1016/j.cub.2010.09.007).

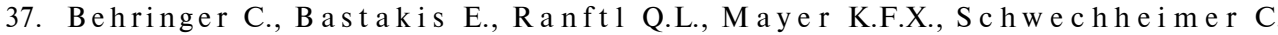
Functional diversification within the family of B-GATA transcription factors through the leucineleucine-methionine domain. Plant Physiol., 2014, 166(1): 293-305 (doi: 10.1104/pp.114.246660).

38. S chwe chheimer C., B e hringer C. B-GATA transcription factors - insights into their structure, regulation and role in plant development. Front. Plant Sci., 2015, 6 (doi: 10.3389/fpls.2015.00090).

39. Parizot B., De Rybel B., B e e ckman T. VisuaLRTC: a new view on lateral root initiation by combining specific transcriptome datasets. Plant Physiol., 2010, 153(1): 34-40 (doi: 10.1104/pp.109.148676).

40. De Rybel B., Audenaert D., Xuan W., Overvoorde P., Strader L.C., Kepinski S., Hoye R., Brisbois R., Parizot B., Vanneste S., Liu X., Gilday A., Graham I.A., Nguyen L., Janse n L., Njo M.F., Inzé D., Bartel B., $\mathrm{B}$ e e c k m a n T. A role for the root cap in root branching revealed by the non-auxin probe naxillin. Nat. Chem. Biol., 2012, 8(9): 798-805 (doi: 10.1038/nchembio.1044).

41. Xuan W., Audenaert D., Parizot B., Möller B.K., Njo Maria F., De Rybel B., De Rop G., Van Isterdael G., Mähönen Ari P., Vanneste S., $\mathrm{B}$ e e c k m a n T. Root cap-derived auxin pre-patterns the longitudinal axis of the Arabidopsis root. Curr. Biol., 2015, 25(10): 1381-1388 (doi: 10.1016/j.cub.2015.03.046).

42. Van Norman J.M., Xuan W., B e e ckman T., Benfey P.N. To branch or not to branch: the role of pre-patterning in lateral root formation. Development, 2013, 140(21): 4301 4310 (doi: 10.1242/dev.090548).

43. Gibbs D.J., Voß U., Harding S.A., Fannon J., Moody L.A., Yamada E., Swarup K., Nibau C., Bassel G.W., Choudhary A., Lavenus J., Bradshaw S.J., Stekel D.J., Bennett M.J., Coates J.C. AtMYB93 is a novel negative regulator of lateral root development in Arabidopsis. New Phytologist, 2014, 203(4): 1194-1207 (doi: 10.1111/nph. 12879).

44. M ölle r B.K., Xuan W., B e e c kman T. Dynamic control of lateral root positioning. Curr. Opin. Plant Biol., 2017, 35: 1-7 (doi: 10.1016/j.pbi.2016.09.001).

45. B e e ckman T., Burssens S., Inze D. The peri-cell-cycle in Arabidopsis. J. Exp. Bot., 2001, 52(Roots Special Issue): 403-411 (doi: 10.1093/jexbot/52.suppl_1.403).

46. Himanen K., Boucheron E., Vanneste S., de Almeida Engler J., Inze D., $\mathrm{B}$ e e c k m a n T. Auxin-mediated cell cycle activation during early lateral root initiation. Plant Cell, 2002, 14(10): 2339-2351 (doi: 10.1105/tpc.004960).

47. DiDonato R.J., Arbuckle E., Buker S., Sheets J., Tobar J., Totong R., Gris afi P., Fink G.R., C e le nz a J.L. Arabidopsis ALF4 encodes a nuclear-localized protein required for lateral root formation. Plant J., 2004, 37(3): 340-353 (doi: 10.1046/j.1365313X.2003.01964.x).

48. Vanneste S., De Rybel B., Beemster G.T.S., Ljung K., De Smet I., Van I ste rdae 1 G., Naudts M., I ida R., Gruissem W., Tasaka M., Inze D., Fukaki H., B e e ckman T. Cell cycle progression in the pericycle is not sufficient for SOLITARY ROOT/IAA14-mediated lateral root initiation in Arabidopsis thaliana. Plant Cell, 2005, 17(11): 3035-3050 (doi: 10.1105/tpc.105.035493).

49. De Smet I., Lau S., Voß U., Vanneste S., Benjamins R., Rademacher E.H., Schlereth A., De Rybel B., Vassileva V., Grunewald W., Naudts M., Levesque M.P., Ehrismann J.S., Inzé D., Luschnig C., Benfey P.N., Weijers D., Van Montagu M.C.E., B ennett M.J., Jürgens G., B e e ckman T. Bimodular auxin response controls organogenesis in Arabidopsis. PNAS, 2010, 107(6): 2705-2710 (doi: 10.1073/pnas.0915001107).

50. Sanz L., Dewitte W., Forzani C., Patell F., Nieuwland J., Wen B., Quelhas P., De Jager S., Titmus C., Campilho A., Ren H., Estelle M., Wang H., Murray J.A.H. The Arabidopsis D-type cyclin CYCD2;1 and the inhibitor ICK2/KRP2 modulate auxin-induced lateral root formation. Plant Cell, 2011, 23: 1-20 (doi: 10.1105/tpc.110.080002). 
51. De m che nko N.P., D e m che n k o K.N. Resumption of DNA synthesis and cell division in wheat roots as related to lateral root initiation. Russian Journal of Plant Physiology, 2001, 48(6): 755-763 (doi: 10.1023/A:1012552307270).

52. Vanneste S., Maes L., De S met I., Himanen K., Naudts M., Inzé D., $\mathrm{B}$ e e ckman T. Auxin regulation of cell cycle and its role during lateral root initiation. Physiologia Plantarum, 2005, 123(2): 139-146 (doi: 10.1111/j.1399-3054.2005.00466.x).

53. Alarcyn M.V., Lloret P.G., Martín-Partido G., S a lgue ro J. The initiation of lateral roots in the primary roots of maize (Zea mays L.) implies a reactivation of cell proliferation in a group of founder pericycle cells. J. Plant Physiol., 2016, 192: 105-110 (doi: 10.1016/j.jplph.2016.02.005).

54. Sugi moto K., Jia o Y., Meyerowitz E.M. Arabidopsis regeneration from multiple tissues occurs via a root development pathway. Dev. Cell, 2010, 18(3): 463-471 (doi: 10.1016/j.devcel.2010.02.004).

55. Casimiro I., Beeckman T., Graham N., Bhale rao R., Zhang H., Case ro P., $\mathrm{S}$ a ndberg G., B e n net t M.J. Dissecting Arabidopsis lateral root development. Trends Plant Sci., 2003, 8(4): 165-171 (doi: 10.1016/S1360-1385(03)00051-7).

56. Jurado S., Abraham Z., Manzano C., Lypez-Torrejyn G., Pacios L.F., D e 1 P oz o J.C. The Arabidopsis cell cycle F-box protein SKP2A binds to auxin. Plant Cell, 2010, 22(12): 3891-3904 (doi: 10.1105/tpc.110.078972).

57. Berckmans B., Vassileva V., Schmid S.P.C., Maes S., Parizot B., Naramoto S., M agy a Z., Ka me i C.L.A., Koncz C., Bogre L., Persiau G., D e Jaeger G., Frim l J., Simon R., B e e ckman T., D e Veyld e r L. Auxin-dependent cell cycle reactivation through transcriptional regulation of Arabidopsis $E 2 F a$ by lateral organ boundary proteins. Plant Cell, 2011, 23(10): 3671-3683 (doi: 10.1105/tpc.111.088377).

58. Nieuwland J., Maughan S., D e wit te W., S c of i eld S., S anz L., Mur ray J.A.H. The D-type cyclin CYCD4;1 modulates lateral root density in Arabidopsis by affecting the basal meristem region. PNAS, 2009, 106(52): 22528-22533 (doi: 10.1073/pnas.0906354106).

59. D e Veyld e r L., B e e k man T., I n z e D. The ins and outs of the plant cell cycle. Nat. Rev. Mol. Cell Biol., 2007, 8(8): 655-665 (doi: 10.1038/nrm2227).

60. Marhavý P., Vanstraelen M., De Rybel B., Zhaojun D., Bennett M.J., $\mathrm{B}$ e e $\mathrm{ckm}$ a n T., B e n k o va E. Auxin reflux between the endodermis and pericycle promotes lateral root initiation. EMBO Journal, 2013, 32(1): 149-158 (doi: 10.1038/emboj.2012.303).

61. Swarup K., Benkova E., Swarup R., Casimiro I., Peret B., Yang Y., Parry G., Nielsen E., De Smet I., Vanneste S., Levesque M.P., Carrier D., James N., Calvo V., Ljung K., Kramer E., Roberts R., Graham N., Marillonnet S., Patel K., Jones J.D.G., Taylor C.G., Schacht man D.P., May S., S a ndberg G., B enfey P., Frim 1 J., Ke r r I., B e e ckman T., Laplaze L., B ennett M.J. The auxin influx carrier LAX3 promotes lateral root emergence. Nat. Cell Biol., 2008, 10(8): 946-954 (doi: 10.1038/ncb1754).

62. Lucas M., Kenobi K., von Wangenheim D., Vo $\beta$ U., Swarup K., De Smet I., Van Damme D., Lawrence T., Péret B., Moscardi E., Barbeau D., Godin C., Salt D., Guyomarc'h S., Stelzer E.H.K., Maizel A., La plaze L., Bennett M.J. Lateral root morphogenesis is dependent on the mechanical properties of the overlaying tissues. PNAS, 2013, 110(13): 5229-5234 (doi: 10.1073/pnas.1210807110).

63. Marhavý P., Montesinos J.C., Abuzeineh A., Van Damme D., Verme e r J.E.M., Duclercq J., Rakusová H., Nováková P., Friml J., Ge ldner N., B enková E. Targeted cell elimination reveals an auxin-guided biphasic mode of lateral root initiation. Genes \& Development, 2016, 30(4): 471-483 (doi: 10.1101/gad.276964.115).

64. Vermeer J.E.M., von Wangenheim D., B a rberon M., Lee Y., Stelzer E.H.K., Maizel A., Geldner N. A spatial accommodation by neighboring cells is required for organ initiation in Arabidopsis. Science, 2014, 343(6167): 178-183 (doi: 10.1126/science.1245871).

65. Blakely L.M., D u rham M., Evans T.A., B lakely R.M. Experimental studies on lateral root formation in radish seedling roots. I. General methods, developmental stages, and spontaneous formation of laterals. Botanical Gazette, 1982, 143(3): 341-352.

66. Laskowski M.J., Williams M.E., Nusbaum H.C., Sus s ex I.M. Formation of lateral root meristems is a two-stage process. Development, 1995, 121(10): 3303-3310.

67. Zhao Y., Christensen S.K., Fankhauser C., Cashman J.R., Cohen J.D., W e ige 1 D., Chory J. A role for flavin monooxygenase-like enzymes in auxin biosynthesis. Science, 2001, 291(5502): 306-309 (doi: 10.1126/science.291.5502.306).

68. Cheng Y., Dai X., Z ha o Y. Auxin biosynthesis by the YUCCA flavin monooxygenases controls the formation of floral organs and vascular tissues in Arabidopsis. Genes \& Development, 2006, 20(13): 1790-1799 (doi: 10.1101/gad.1415106).

69. De Smet I., Vassileva V., De Rybel B., Levesque M.P., Grunewald W., Van Damme D., Van Noorden G., Naudts M., Van Isterdael G., De Clercq R., Wang J.Y., Meuli N., Vanneste S., Friml J., Hilson P., Jurgens G., Ingram G.C., 
Inze D., Benfey P.N., Beeckman T. Receptor-like kinase ACR4 restricts formative cell divisions in the Arabidopsis root. Science, 2008, 322(5901): 594-597 (doi: 10.1126/science.1160158).

70. Fernández-Marcos M., Desvoyes B., Manzano C., Liberman L.M., Benfey P.N., del Pozo J.C., Gutierrez C. Control of Arabidopsis lateral root primordium boundaries by MYB36. New Phytologist, 2016, 213(1): 105-112 (doi: 10.1111/nph.14304).

71. Gu ly a e v V.A. Botanicheskii zhurnal, 1964, 49(10): 1482-1485 (in Russ.).

72. D u b rovs ki i I.G. Botanicheskii zhurnal, 1987, 72(2): 171-176 (in Russ.).

73. De m chenko K.N., De m c he nko N.P. Changes of root structure in connection with the development of lateral root primordia in wheat and pumpkins. In: Recent advances of plant root structure and function. Developments in plant and soil sciences. V. 90. O. Gašparíková, M. Čiamporová, I. Mistrík, F. Baluška (eds.). Springer, Dordrecht, 2001: 39-47 (doi: 10.1007/978-94017-2858-4_5).

74. Dubrovski i I.G. Ontogenez, 1986, 17(2): 176-189 (in Russ.).

75. Mallory T.E., Chi ang S.-H., Cutte r E.G., G ifford E.M. Sequence and pattern of root formation in five selected species. Am. J. Bot., 1970, 57(7): 800-809.

76. O'D e 11 D.H., F o a r d D.E. Presence of lateral root primordia in the radicle of buckwheat embryos. Bulletin of the Torrey Botanical Club, 1969, 96(1): 1-3 (doi: 10.2307/2484002).

77. S e a g o J.L. Developmental anatomy in roots of Ipomoea purpurea. 2. Initiation and development of secondary roots. Am. J. Bot., 1973, 60(7): 607-618.

78. $\mathrm{C}$ h a rlto $\mathrm{n}$ W.A. Distribution of lateral roots and sequence of lateral initiation in Potenderia cordata L. Botanical Gazette, 1975, 136(3): 225-235.

79. C low e s F.A.L. Origin of epidermis and development of root primordia in Pistia, Hydrocharis and Eichhornia. Annals of Botany, 1985, 55(6): 849-857.

80. D u b rovsky J.G., La s k ow s k i M. Lateral root initiation. In: Encyclopedia of applied plant sciences (Second edition). B. Tomas, B.G. Murray, D.G. Murphy (eds.). Academic Press, Oxford, 2017: 256-264 (doi: 10.1016/B978-0-12-394807-6.00126-X).

81. Il ina E.L., Logachov A.A., Lap laze L., De mchenko N.P., Pawlowski K., D e m c he n k o K.N. Composite Cucurbita pepo plants with transgenic roots as a tool to study root development. Annals of Botany, 2012, 110(2): 479-489 (doi: 10.1093/aob/mcs086). 